\title{
Adrenal Tuberculosis Leading to Acute Adrenal Insufficiency
}

\author{
Nitu Sharma ${ }^{1}$, Yashika Bhatia ${ }^{2}$ \\ ${ }^{1}$ Associate Professor, Pathology, Command Hospital, Udhampur \\ ${ }^{2}$ Senior Resident, Pathology, Command Hospital, Udhampur \\ Corresponding Author: Yashika Bhatia
}

\begin{abstract}
Background: Tuberculosis is the 'world's largest killer' amongst infectious diseases overtaking HIV in 2014. Tuberculosis can affect the kidneys and adrenals as either primary infection or secondary dissemination from other organs. Tuberculosis in adrenals manifests in the acute phase leading to primary adrenal insufficiency, which is generally catastrophic leading to death.

Case Report: We present an unusual case of a 42 years' old man, presented \& managed as a case of acute gastroenteritis. Patient had a fulminant course and succumbed to his illness. Autopsy revealed Bilateral Adrenal Tuberculosis

Conclusion: Adrenal tuberculosis has the potential of causing acute adrenal deficiency leading to Addisonian crisis and consequent mortality.
\end{abstract}

Key Words: Adrenal tuberculosis, Addisonian crisis, acute adrenal insufficiency

\section{INTRODUCTION}

Tuberculosis is the 'world's largest killer' amongst infectious diseases overtaking HIV in 2014. One-quarter of the world population is infected with tuberculosis with $1 \%$ newly infected population annually. Tuberculosisassociated mortality is increasing worldwide due to enhanced transmission due to rise in immunocompromised population and emergence of drug resistance. The estimated incidence of TB in India was 2.1 million cases in 2013, 16 per cent of which were new extrapulmonary tuberculosis (EPTB) cases, equating to 336,000 people with EPTB. (1) The burden of EPTB is high ranging from 15-20 per cent of all TB cases in HIV-negative patients, while in HIVpositive people, it accounts for 40-50 per cent of new TB cases. ${ }^{(2)}$

\section{Extrapulmonary tuberculosis} affecting internal organs and sequestered sites presents late and is fret with numerous complications. Almost each and every organ of the body can be affected by tuberculosis except hair, nail and enamel. Most common extrapulmonary tuberculosis is tubercular lymphadenitis followed by pleural effusion. Other five most common locations of extrapulmonary TB being the liver, spleen, kidneys, adrenal glands and bones. ${ }^{(3)}$

Tuberculosis can affect the kidneys and adrenals as either primary infection or secondary dissemination from other organs. Isolated adrenal tuberculosis accounts for less than $2 \%$ of adrenal incidentalomas. ${ }^{(4)}$ Tuberculosis in adrenals can invariably manifest in the acute phase accounting for about $7-20 \%$ percent of cases of primary adrenal insufficiency in developed countries, which is generally catastrophic leading to death. ${ }^{(5)} \mathrm{We}$ present a case of adrenal tuberculosis manifesting as Addisonian crisis and acute adrenal insufficiency leading to mortality in a short span of admission to a tertiary-care teaching hospital. 


\section{CASE REPORT}

A 42 years old man, known case of old pleural effusion, was referred to tertiarycare teaching hospital from a secondarycare hospital with complaints of pain epigastrium and vomiting of 15 days duration. Patient was initially managed with antiemetics with which he improved marginally, but came back again with same complaints. Examination revealed restlessness, febrile toxic look, tachycardia $134 / \mathrm{min}$, normal blood pressure with no postural variation and was promptly admitted to acute care.

Routine haemogram, clinical chemistry, and upper gastrointestinal endoscopy were within normal limits with haemoglobin of $10.5 \mathrm{mg} / \mathrm{dl}$, Total leucocyte count $8800 / \mathrm{cu} \mathrm{mm}$ with neutrophils $76 \%$ and lymphocytes $5 \%$, platelets $177,000 / \mathrm{cu}$ $\mathrm{mm}$, normal peripheral blood smear. Renal function tests, and liver function tests were within normal limits. $\mathrm{He}$ deteriorated rapidly over the next 48 hrs, developed generalized tonic clonic seizures and finally went into a state of status epilepticus. The serum electrolytes done showed serum sodium of $128 \mathrm{meq} / \mathrm{l}$ (Normal:130$150 \mathrm{meq} / \mathrm{l})$ and a serum Potassium of 5.8 meq/l (Normal: 3.5-5.5 meq/1). His seizures were attributed to this hyponatremic state. Urine was acidic with increased protein and leucocytes. Arterial blood gas, $\mathrm{pH}$ and oxygen saturation was maintained. $\mathrm{He}$ worsened within next $24 \mathrm{hrs}$ and on daythree, he developed sudden bradycardia with refractory hypotension followed by asystolic cardiac arrest from which he could not be revived even after aggressive resuscitative measures.

A complete autopsy revealed collapsed left lung which was tightly adherent to the chest wall. Both the adrenals were enlarged and converted into bags of thick white necrotic material. Both adrenals were stuck to the upper pole of the kidneys. Histopathological examination of lungs showed areas of pulmonary hemorrhage, edema and aspiration pneumonitis. Both the adrenals were completely replaced by palisading epitheloid cell granulomas with abundant caseation and scattered Langhans giant cell. The adrenal granulomas extended through the perirenal fat into the upper pole of both kidneys. However, no acute tubular necrosis or destruction of renal parenchyma was seen. Bilateral adrenal parenchymal tissue subjected to IS6110 target real-time polymerase chain reaction revealed Mycobacterium tuberculosis complex.

\section{DISCUSSION}

Addison's disease is a rare disorder with an estimated prevalence of approximately 120 individuals in one million. (7,8,9) Adrenal glands can be primarily affected by infections such as tuberculosis and Histoplasmosis, despite located in the retroperitoneum. When adrenal insufficiency was first identified by Dr. Thomas Addison in 1849, tuberculosis was found at autopsy in 70 to 90 percent of cases. As the incidence of tuberculosis declined and treatment improved, the incidence of adrenal tuberculosis has declined. ${ }^{(8,10)}$ Primary adrenal insufficiency or Addison's disease affects about 1 in 100,000 people. Adrenal insufficiency occurs when at least 90 percent of the adrenal cortex has been destroyed. As a result, both glucocorticoid (cortisol) and mineralocorticoid (aldosterone) hormones are lacking. About $70-80 \%$ of reported cases of Addison's disease are caused by autoimmune disorders, $20 \%$ by tuberculosis and rest are idiopathic. ${ }^{(8,9,11)}$

In most cases, symptoms are severe enough so that patients seek medical treatment before a crisis occurs. However, in about 25 percent of patients, symptoms first appear during an Addisonian crisis which includes (a) sudden penetrating pain in the lower back, abdomen, or legs (b) severe vomiting and diarrhea (c) dehydration (d) low blood pressure (e) loss of consciousness. Oligosymptomatic presentation is possible as in this case. ${ }^{(11)}$ Left untreated, an Addisonian crisis can be fatal. Case reports have shown it is very difficult to diagnose primary adrenal 
tuberculosis manifesting as Addisonian crisis. $50 \%$ cases of active tuberculosis of adrenal gland are diagnosed post-mortem with frank tuberculosis being evident on macroscopic examination of the adrenal glands in $46 \%$ patients. (9) Lam and Lo reported that adrenal tuberculosis is found in $6 \%$ of patients with active tuberculosis. The adrenal glands were the only organs involved in active TB in $25 \%$ of cases, and bilateral involvement was seen in $69 \%$. ${ }^{(3)}$ In another study in China over the 28 years, active tuberculosis was present in 871 of 13492 patients at autopsy. Adrenal tuberculosis was seen in 52 of the 871 patients $(6 \%)$ with active tuberculosis at autopsy and in 3 patients at adrenalectomy. The adrenal gland was the only organ involved by active tuberculosis in 14 of these 55 patients $(25 \%$; 35 men, 20 women). (12) Primary adrenal tuberculosis without involvement of other organs and early mortality is rare and only a few cases have been reported. ${ }^{(13)}$

\section{CONCLUSION}

Adrenal tuberculosis is rare although has the potential of causing acute adrenal deficiency leading to Addisonian crisis and consequent mortality. A high index of suspicion, early diagnosis, early initiation of replacement steroid therapy, and antitubercular therapy are essential for management and favourable prognosis.

\section{Acknowledgement: None}

\section{Conflict of Interest: None}

\section{Source of Funding: None}

\section{REFERENCES}

1. New Delhi: World Health Organization, Regional Office for South-East Asia; 2014. World Health Organization. Tuberculosis control in the south-east Asia region annual TB report 2015; p. 61.
2. Sharma SK, Mohan A. Extrapulmonary tuberculosis. Indian J Med Res. 2004; 120:316-53.

3. Lam KY, Lo CY. A critical examination of adrenal tuberculosis and a 28-year autopsy. Clin Endocrinol (Oxf). 2001;54(5):633-9.

4. Boukani N, BentalebD, Belgadir $\mathrm{H}$, Amriss O, Moussali N, Elbenna N. Bilateral adrenal tuberculosis: about a case. Pan Afr Med J. 2018 Apr 13; 29:212.

5. Williams GH, Dluhy, RC. Disorders of the adrenal cortex. In: Braunwald E, ed.

6. Harrison's Principles of Internal Medicine. 15th ed. New York: McGrawHill Professional; 2001: 2084-2105

7. Bhatia E, Jain SK, Gupta RK, Pandey R. Tuberculous Addison's disease: Lack of normalization of adrenocortical function after anti-tuberculous chemotherapy. Clin Endocrinol (Oxf). 1998;48(3):3559.

8. Herman Trianto, Nurria Betty, Laksmi Sasiarini, Rulli Rosandi, Putu Arsana, Djoko Soeatmadjj, Achmad Rudjjanto.Acute Adrenal Insufficiency as the Primary Manifestation of Extrapulmonary Tuberculosis: A case Report. Journal of the ASEAN Federation of Endocrine Societies.Vol 31. No 1

9. Pathophysiology of Disease: An Introduction to Clinical Medicine by William Francis Ganong, Stephen J. McPhee 5 th edition pg609

10. Kevin Klauer. Adrenal Insufficiency and Adrenal Crisis. eMedicine from WebMed updated on Jan 30, 2007.

11. Ten S, New M, Maclaren N. Clinical Review 130: Addison's disease 2001. Journal of Clinical Endocrinology \& Metabolism. 2001; 86(7):2909-2922.

12. Dr. George P. Chrousos Dr. Judith Fradkin. Endocrine and Metabolic Disease Information Centre.NIDDK. NIH Publication No. 04-3054 June 2004

13. A critical examination of adrenal tuberculosis and a 28-year autopsy experience of active tuberculosis. Lam 
KY, Lo CY.Faculty of Medicine, University of Hong Kong, Hong Kong. Clin Endocrinol (Oxf) 2001 May; 54(5):633-9

14. S Ward and CC Evans. Sudden death due to isolated adrenal tuberculosis. How to cite this article: Sharma N, Bhatia Y. Adrenal tuberculosis leading to acute adrenal insufficiency. Int J Health Sci Res. 2021; 11(6):148-151. DOI: https://doi.org/ Postgraduate Medical Journal, 1985, Vol 61, 635-636 